\title{
The NIH entitlement program
}

A $\mathrm{n}$ article was published in the New York Times on 22 September by Gardner Harris entitled "Debate flaring over grants research". It was based on a US Government Accountability office report that examined grant management practices at the NIH. In essence, this article discusses whether or not the NIH grant administrators are right to reach down to 'make exceptions' and fund grants with worse NIH scores to support new young investigators. Apparently, the average age of investigators has risen from 35 years in 1980 to 41 years in 2009 , so such steps are necessary. The American Cancer Society goes even further: anyone over the age of 45 need not apply! What happened to the merit system? If your goal is to find new knowledge that leads to the eradication of disease shouldn't we be funding the best and the brightest researchers, whatever their age? Harris says, "There has been a growing chorus of complaints over the years that the agencies scientific review process is deficient-that is, fails to finance high-risk research; that projects must effectively be half done before financing is approved; that cliques control the process; and that reviewers are rarely the field's leading lights".

Anyone involved in the NIH grant system knows that all these complaints are true. I speak from experience; I ran the largest component of that grant program at the National Cancer Institute for 15 years. The essence of the problem is that universities are addicted to R01 grants, and so the grant system has become an entitlement program. Without an R01 grant, it is difficult for an investigator to attain tenure. What has surprised-even shocked-me is that what investigators do with those grants is often secondary to the fact that they got them. Supporting high-risk research is not the major goal. The grant peer-review process has become the major arbiter of tenure, and incumbents do have an unfair advantage. Peer-review committees, each made up of grant holders, give priority to established investigators similar to themselves. Scientists will always admit to other scientists (albeit not in public) that they don't submit their best and newest ideas in grant proposals but instead suggest ideas that have some data to support them.

Left to their own devices, young investigators do well on their own. Their ideas are often fresh and, in a purely merit-based grant system, they can outcompete those of an incumbent. New investigators are at a disadvantage under the grant system as it is presently constructed; however, this disadvantage is of the NIH's own making. The NIH distorts the system even further: it decries 'targeted research' but regularly influences the research process by issuing requests for grant applications in specific (targeted) areas with set-aside funds. The areas selected are what the Congress, NIH staff, or a board of advisors thinks is the best way to spend grant funding. I have watched young investigators change their research interests not because they thought an NIH request for grant applications identified an interesting area but because they needed to follow pools of money. So much for the storied primacy of "investigator-initiated research".

To keep Congress anxious about how many grants are funded each year, the NIH keeps the percentage of approved grants that are actually funded artificially low. NIH scores approved grants on a system of one to five, with one being the best score and five the worst. A grant can also be disapproved, although few ever are. Many grants are given scores of three, four or five that indicate they shouldn't be funded even if the investigator is young and money is available. Expressed another way, no matter how much money we had, we could find better ways of spending it than funding grants with bad scores. Instead of funding only $21 \%$ of approved applications, the NIH are more often funding $40-50 \%$ of good applications. That's not too bad, really. Funding grants with poor scores could get one into bad territory.

It is in the best interests of both universities and the $\mathrm{NIH}$ to leave the system as is. However, the NIH has so distorted the peer-review process that it is now faced with dilemmas such as funding young investigators just because they are young and not because of the merit of their ideas. The grant system has become an end in itself, instead of a means to an end. A quote from Churchill about democracy is often paraphrased to defend the current system as "the worst system ever invented except for every other system". This may be true for democracy but not the NIH peer-review system.

doi:10.1038/nrclinonc.2009.164

\section{$4 \mathrm{It}$ is in the best interests of both universities and the NIH to leave the system as is 77}

Vincent T. DeVita Jr is the Editor-in-Chief of Nature Reviews Clinical Oncology.

Competing interests The author declares no competing interests. 